\title{
Revista Brasileira de Enfermagem REBEn \\ Memória coletiva da Associação Brasileira de Enfermagem - Seção Piauí
}

HISTÓRIA DA ENFERMAGEM

\author{
Collective memory of the Brazilian Nursing Association - Piaui Section \\ Memória colectiva de la Asociación Brasileña de Enfermería - Sección Piauí
}

\section{Benevina Maria Vilar Teixeira Nunes \\ Doutora em Enfermagem. Professora da Universidade Federal do Piauí (UFPI), Teresina, PI. Coordenadora do Curso de Enfermagem da NOVAFAPI. bnunes@novafapi.com.br}

Ana Maria Ribeiro dos Santos

Enfermeira. Mestre em enfermagem. Professora do Departamento de Enfermagem da UFPI, Teresina, PI e NOVAFAP. Coordenadora da Comissão de Educação daABEn-PI

\section{Maria Eliete Batista Moura}

Doutora em enfermagem. Professora do Departamento de Enfermagem da UFPI,

Teresina, PI. Coordenadora de Pósgraduação e Pesquisa da NOVAFAPI.

\section{Maria Enóia Dantas da Costa e Silva}

Mestre em enfermagem. Professora da NOVAFAPI, Teresina, PI. Enfermeira da Estratégia Saúde da Família no município

de Teresina.

\section{Claudete Ferreira de Souza Monteiro}

Doutora em enfermagem. Coordenadora do Programa de Mestrado em Enfermagem do Departamento de Enfermagem da UFPI, Teresina, $P I$

\section{Maria do Livramento Carvalho}

Doutora em enfermagem. Professora do Departamento de Enfermagem da UFPI, Teresina, PI.
Submissão: $08 / 05 / 2007$

Aprovação: 28/06/2007

\section{RESUMO}

Estudo histórico social que objetivou apreender as representações sociais sobre a prática associativa presentes na memória coletiva dos membros da ABEn-PI. Teve como fonte primária 94 atas da ABEn-PI elaboradas nos períodos de 1959 a 1970 e 1995 a 2005 e analisadas de acordo com análise de conteúdo categorial temática. As representações sociais apreendidas diziam respeito a conhecimentos, posicionamentos e sentimentos sobre ensino de enfermagem, religiosidade e homenagens e lutas políticas da ABEn. A circulação desses conhecimentos, posicionamentos e sentimentos entre os componentes da associação, mostraram a difusão das representações sociais determinando as condutas dessas enfermeiras como membros da ABEn-PI.

Descritores: História da enfermagem; Sociedades de enfermagem; Memória.

\section{ABSTRACT}

Historical and social study that aimed at obtaining the social representations about associative practice present at the collective memory of the members from ABEn-PI. Its primary source were 94 minutes of ABEn-PI created from 1959 to 1970 and from 1995 to 2005 and analyzed according to a thematic analysis of categorical content. The social representations obtained were about knowledge, positioning and feelings about nursing teaching, religiosity and honoring and political fights of ABEn. The dissemination of these knowledge, positioning and feelings among the members of the association, showed the spread of social representations determining the behavior of these nurses as ABEn-PI members.

Descriptors: Nursing history; Nursing societies; Memory.

\section{RESUMEN}

Estudio histórico y social que objetivó aprehender las representaciones sociales sobre la práctica asociativa presentes en la memoria colectiva de los miembros de la ABEn-PI. Tuvo como fuente primaria 94 actas de la ABEn-PI hechas de 1959 a 1970 y de 1995 a 2005 y analizadas de acuerdo con análisis de contenido categorial temática. Las representaciones sociales aprehendidas eran en respecto a conocimientos, posicionamientos y sentimientos acerca de la enseñanza de enfermería, religiosidad y homenajes y luchas políticas de la ABEn. La diseminación de esos conocimientos, posicionamientos y sentimientos entre los miembros de la asociación, mostraron la difusión de las representaciones sociales determinando las conductas de esas enfermeras como miembros de la ABEn-PI.

Descriptores: Historia de la enfermería; Sociedades de enfermería; Memoria.

Nunes BMVT, Santos AMR, Moura MEB, Costa e Silva MED, Monteiro CFS, Carvalho ML. Memória coletiva da Associação Brasileira de Enfermagem - Seção Piauí. Rev Bras Enferm 2007 jul-ago; 60(4):464-9.

\section{INTRODUÇÃO}

O presente estudo tem relação com outras pesquisas realizadas no sentido de resgatar a memória da enfermagem piauiense, visando conhecer e escrever a história desta profissão no Estado.

Na busca de informações sobre a trajetória da profissão no contexto local é possível apontar que a mesma está silenciada na literatura produzida na área de saúde. Entretanto, existe a possibilidade de reconstruir parte desse passado via o resgate das representações sociais presentes na memória coletiva dos grupos que ainda permanecem vivos e da sistematização dos documentos contidos em arquivos, no sentido de dar visibilidade histórica à profissão antes que o desgaste natural do tempo apague registros importantes.

Dessa forma, a visão que se tem do passado é como um vidro estilhaçado antes composto de inúmeras cores e partes e que compete à história e a memória compreendê-lo, por meio da análise dos 
fragmentos existentes, evitando que os seres humanos percam referenciais fundamentais à construção das identidades coletivas. A história, como campo fertilizador da memória, ajuda a sociedade encontrar na própria história "subsídios necessários ao processo de busca de identidades inerente ao ser humano"(1).

Para dar conta da questão teórico-conceitual do estudo aplicou-se o conceito de memória coletiva na sua aproximação com as representações sociais, como "um conjunto de representações sociais sobre o passado". Essa aproximação se justifica tendo em vista que "a imagem do passado é produzida, conservada, elaborada e transmitida por um grupo através da interação de seus membros"(2).

As representações sociais constituem sistema de valores, noções e práticas com dupla tendência: instaurar uma ordem que permite aos indivíduos a possibilidade de se orientar no meio - ambiente social, material e de dominá-lo bem como assegurar a comunicação entre os membros de uma comunidade, propondo-lhes códigos que possibilite trocar, nomear e classificar de maneira unívoca as partes de seu mundo, de sua história individual ou coletiva $^{(3)}$.

Reconstruir a história de um grupo social, no caso desse estudo, da ABEn-PI, utilizando-se para isso registros da memória de pessoas que viveram em determinadas épocas está se resgatando representações sociais, pois tem a ver com o modo pelo qual as pessoas descrevem a sociedade ou aquele agrupamento social tal como pensam que ela é ou que gostariam que fosse.

Partindo desse entendimento e da inserção das autoras deste estudo na Associação Brasileira de Enfermagem-Secção Piauí, como membros da atual diretoria e, portanto, conhecedoras da riqueza de fontes documentais da associação, ainda não estudados, objetivou-se apreender as representações sobre a prática associativa dos membros da ABEn-PI, por meio de seus conhecimentos, sentimentos e posicionamentos presentes na memória coletiva e comparar as representações nos dois recortes de tempo do estudo.

\section{METODOLOGIA}

O estudo é de natureza histórico-social e teve como fonte primária de dados 94 atas da ABEn-PI elaboradas pelos membros das diretorias, em dois períodos: 63 atas, no primeiro recorte temporal, de1959 a 1970, compreendendo desde a criação da associação à sua primeira década de funcionamento e 31 atas, no segundo, de 1995 a 2005, período em que esta associação se consolida como instituição de classe dos enfermeiros, no Estado.

As 94 atas foram lidas, digitadas integralmente e submetidas às etapas de pré-analise, exploração e tratamento e tratamento dos dados de acordo com análise de conteúdo temática categorial ${ }^{(4)} \mathrm{E}$, dessa forma, todo o conteúdo do material documental foi organizado por similaridade semântica em dois corpus que deram origem a cinco categorias e a treze subcategorias do estudo, nos dois períodos, apresentadas no Quadro 1.

Os resultados foram analisados também com base no conceito de representações sociais, como sendo um sistema de valores, de noções e de práticas tendo uma dupla tendência: antes de tudo instaurar uma ordem que permite aos indivíduos a possibilidade de se orientar no meio-ambiente social, material e de dominá-lo. Em seguida, de assegurar a comunicação entre os membros de uma comunidade, propondo-lhes um código de troca para nomear e classificar de maneira unívoca, as partes de seu mundo, de sua história individual ou coletiva ${ }^{(3)}$.

Neste sentido, a construção e o funcionamento das representações sociais ocorrem mediante dois processos: objetivação e ancoragem; sendo que objetivar consiste em materializar as abstrações, corporificar os pensamentos, tornar físico o invisivel, enfim, transformar em objeto o que é representado. $E$, ancorar permite a incorporação do que é desconhecido ou novo a uma rede de categorias usuais. Logo, se a objetivação explica como os elementos representados de uma teoria se integram, como termos da realidade social, a ancoragem permite compreender a maneira na qual eles contribuem para exprimir e constituir as relações sociais ${ }^{(3)}$.

\section{REPRESENTAÇÕES SOCIAIS DA MEMÓRIA COLETIVA DA ABEn-PI}

O conteúdo das atas da ABEn-Pi evidenciou as representações sociais que circulavam entre os membros daquela associação, ressaltando as representações consensuais do grupo sobre a profissão, as quais emergem do conjunto de conhecimentos, posicionamentos e sentimentos comuns àqueles grupos que orientavam a construção da prática associativa das enfermeiras, uma vez que as representações sociais compreendem a imbricação e a articulação entre atividade cognitiva e as condições sociais em que são forjadas ${ }^{(3)}$.

\begin{tabular}{|c|c|}
\hline 1959 a 1970 & 1995 a 2005 \\
\hline \multicolumn{2}{|c|}{ 1. Categoria - Conhecimento sobre o Ensino da Profissão } \\
\hline Subcategorias & Subcategorias \\
\hline $\begin{array}{l}\text { 1.1.Informações sobre a legislação do ensino de enfermagem. } \\
\text { 1.2.Conhecimento sobre o projeto de criação de escolas de enfermagem. }\end{array}$ & $\begin{array}{l}\text { 1.1. Capacitação de enfermeiros e alunos para a iniciação a pesquisa. } \\
\text { 1.2. Divulgação dos canais de publicações científicas. }\end{array}$ \\
\hline \multicolumn{2}{|c|}{2 - Categoria - Posicionamentos Frente ao Ensino da Profissão } \\
\hline $\begin{array}{l}\text { 2.1. Atitude crítica em relação às condições de criação de escolas de } \\
\text { enfermagem na realidade local. }\end{array}$ & $\begin{array}{l}\text { 2.1.Cursos de capacitação técnica dos profissionais e alunos de } \\
\text { enfermagem }\end{array}$ \\
\hline \multicolumn{2}{|c|}{ 3 - Categoria - Sentimentos em Relação ao Ensino da Profissão } \\
\hline \multicolumn{2}{|c|}{$\begin{array}{l}\text { 3.1.Autonomia quanto processo de formação do ensino de enfermagem } \\
\text { 3.2. Insegurança quanto às condições estruturais de criação de escola superior de enfermagem. }\end{array}$} \\
\hline \multicolumn{2}{|c|}{ 4- Categoria - Posicionamentos Sobre as Lutas políticas da ABEn } \\
\hline $\begin{array}{l}\text { 4.1 Conhecimento das lutas da ABEN } \\
\text { 4.1 Difusão da profissão na sociedade }\end{array}$ & 4.1 Representação da enfermagem em Conselhos de Saúde. \\
\hline \multicolumn{2}{|c|}{ 5- Posicionamento de Culto a Reliqião e Homenaqens } \\
\hline 5.1.Proximidade entre a fé e a profissão & $\begin{array}{l}\text { 5.1 Homenagens Ex-presidentes da ABEn e as } \\
\text { enfermeiras aposentados }\end{array}$ \\
\hline
\end{tabular}

Quadro 1. Sistematização do conteúdo textual das atas da ABEN-PI. 
Apresentaremos a seguir o conjunto de categorias elaboradas a partir dos conteúdos das atas:

\subsection{Conhecimento sobre o Ensino da Profissão}

Essa categoria apresenta o conhecimento dos membros da ABEn-P relativo ao o ensino da profissão. Nas atas do período de 1959 a 1970 foram sistematizadas duas subcategorias: informações sobre a legislação do ensino de enfermagem e informações sobre o projeto de criação de escolas de enfermagem na realidade local.

Com base nas unidades de contexto mais freqüentes do primeiro grupo de atas, inferimos que os conteúdos dessa categoria revelam as representações dos membros da $A B E n$ sobre o ensino da profissão, tanto em relação às informações sobre a legislação do ensino médio, quanto em relação ao conhecimento sobre o projeto de criação de uma escola superior de enfermagem na realidade piauiense.

O conhecimento da legislação do ensino de enfermagem é mencionado em várias unidades de contexto como revelam os trechos das atas de $n^{0} 04 \mathrm{e} 11$ :

A diretora da Escola de Auxiliar de Enfermagem Irmã Maria Antoinette Blanchot solicitou a opinião sobre o currículo das escolas de auxiliares, dizendo achar muito resumido. Ainterrogada informou que as cadeiras constantes na Lei 775, de 6 de agosto de 1949 em vigor, para o ensino da enfermagem, são realmente em numero resumido, mas poderão ser interpretadas amplamente, por isso, cada escola é livre de acrescentar outras matérias que julgar necessária ao preparo eficiente de suas alunas, no entanto, jamais, poderão eliminar ou reduzir o currículo determinado

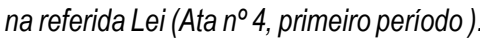

A sócia irmã Carolina Fernandes tratando de problemas de interesse da classe enfatizou o assunto do seminário sobre bases e diretrizes do ensino de enfermagem em que grande interesse pelo caso tomou quando esteve conosco a presidente daABEn, dona Marina de Andrade Rezende (ata 11, primeiro período).

A representação sobre o ensino de enfermagem nesse agrupamento de atas (primeiro período), está ancorada na prática de ensino de enfermagem da maioria dos membros da associação que também era professor da Escola de Auxiliar de Enfermagem Maria Antoinnet Blanchot e, por conseguinte, no conhecimento da legislação de ensino vigente, naquela época.

Convém enfatizar, que a proximidade dos membros da ABEn-PI com esse conhecimento deveu-se ao fato da própria da Associação Brasileira de Enfermagem ter suas origens no ensino de enfermagem, fato que se reproduziu na realidade piauiense, em que a ABEn-PI foi criada pela Irmã Abrahyde Alvarenga, egressa da Escola de Enfermagem Anna Nery, da turma de $1942^{(5)}$.

A circulação desse conhecimento entre os grupos de pertença dessa categoria mostra a difusão do conhecimento que mantêm o conjunto de representações sociais dessa categoria, determinando as condutas desses sujeitos.

Em outra perspectiva, as unidades de análise enunciam como as enfermeiras tinham uma preocupação com a possibilidade de criação de escolas de enfermagem, tanto de ensino médio, como ensino superior na realidade local. Vale ressaltar que entre a década de 60 e 70, o Piauí tinha uma única escola de ensino médio de enfermagem, a Escola Auxiliar de Enfermagem MariaAntoinnete Blanchot.

Na década de 60 existiu interesse do Governo do Estado em criar um curso superior de enfermagem ${ }^{(6)}$, sendo que esse assunto foi motivo de discussão nas reuniões da $A B E n$ o que revela o conhecimento do grupo sobre os interesses da categoria, conforme trecho da ata:

Foi esclarecido pela irmã que houve solicitação de médicos interessados em saber o currículo de uma faculdade de enfermagem dizendo ter sido sabedora que já fora criada a escola em mil novecentos e sessenta e que o governo está interessado em fazer funcionar essa faculdade brevemente (Ata 42, primeiro período).

No segundo período do estudo, 1995 a 2005, na categoria conhecimento sobre 0 ensino da profissão, foram sistematizadas duas subcategorias: capacitação de enfermeiros e alunos para a iniciação a pesquisa e divulgação dos canais de publicações científicas.

Ao comparar o conhecimento das enfermeiras sobre o ensino da profissão foi verificado que no segundo período de tempo estudado, as preocupações dos sócios da ABEn-PI não estavam relacionadas ao ensino formal da profissão, mas ao ensino da iniciação à pesquisa e divulgação dos canais de publicação cientifica. Nesse sentido, foram promovidos pela Associação curso de metodologia da pesquisa como demonstram as unidades de contexto:

A presidente comunicou em seguida a realização do curso: introdução à Pesquisa na Enfermagem, no período de 27/09 à 08/11/95, das $15: 30$ às 18:00 horas, às segundas e quartas - feiras, no Centro Formador de Recursos Humanos Carlyle Guerra de Macedo promovida pelaABEn Seção Piauí com o apoio da Pró - Reitoria de Extensão e Pesquisa da UFPI, com 40 vagas. (ata 15)

Essa preocupação com a pesquisa tinha relação com o próprio grupo que estava dirigindo a associação, naquele momento, que era ligado ao Departamento de Enfermagem da Universidade Federal do Piauí e, portanto, estava mais diretamente inserido no contexto da pesquisa como mostra as unidades de contexto;

A presidente comunicou que participou do IV Encontro da Rede de Pesquisa Norte e Nordeste sobre Mulher e Relação de Gênero, em João Pessoa-PB. Com passagem e hospedagem vinda da REDOR, pois a mesma coordenava 03 (três) pesquisas no Piauí.

Por outro lado, esse conhecimento ensejava também a divulgação dos canais de publicação:

A senhora presidente informou o recebimento de correspondência do CNPq quanto à solicitação da publicação dos Anais do XII Enf. Nordeste, onde foi indeferido (Ata $n^{0} 15,2^{\circ}$ período).

No que diz respeito aos informes foi apresentada a ficha de inscrição da REBEn com prazo sem aumento até 31 de julho próximo (ata $n^{0} 11$, segundo período).

As questões da pesquisa também fazem parte das lutas da Associação Brasileira de Enfermagem e é louvável que os membros da ABEn-PI estivessem preocupados com a relevância da questão.Todavia ao se analisar o conhecimento das sócias sobre o ensino da profissão, no conjunto de atas do segundo período, percebeu-se que houve um distanciamento em relação ao primeiro período no que diz respeito as questões gerais do ensino de enfermagem.

Principalmente, porque era um momento em que as escolas deveriam implementar o Currículo Mínimo aprovado em 1994, o qual foi motivo de discussão nacional promovida pela ABEn, ao realizar ampla discussão nacional com outras entidades da classe e escolas de enfermagem do país,e apresentar uma proposta curricular que foi encaminhada ao MEC e aprovada em 15 de dezembro de $1994^{(7)}$. Vale ressaltar, que posteriormente, em 2004 a ABEn-PI promoveu o Seminário Nacional de Educação em Enfermagem (SENADEn), retomando a discussão sobre o assunto.

\subsection{Posicionamentos Frente ao Ensino da Profissão}

Esta categoria reúne as unidades de contexto referentes aos 
posicionamentos positivos e negativos do grupo de enfermeiras da ABEn$\mathrm{PI}$, no período compreendido entre 1959 a 1970, sendo os conteúdos dessas unidades agrupados semanticamente, em apenas uma subcategoria, tratando da atitude crítica dessas enfermeiras sobre as condições de criação de escolas de enfermagem na realidade local e sobre a qualificação do corpo docente para esses cursos.

Estes conteúdos revelam os posicionamentos relacionados ao cumprimento dos aspectos legais da formação dos profissionais de enfermagem, naquele momento, que era voltado ao ensino médio, todavia, apontando preocupações com o ensino de graduação, em que o projeto de criação do curso, neste nivel, estava sob a responsabilidade da categoria médica. Assim, manifestam o posicionamento positivo em partilhar destas responsabilidades, como sendo do alcance dos profissionais enfermeiros. Tais posicionamentos se confirmam nos trechos extraídos das atas, desse período:

(...) foi levantado o problema do funcionamento do curso técnico de enfermagem na Escola Industrial do Piauí. Após alguns comentários sobre o assunto, todas as enfermeiras presentes deram o parecer contra tal iniciativa, ficando decidido se procurar o diretor da referida escola, para esclarecê-lo sobre as exigências legais de funcionamento desse curso e que seria importante verificar as possibilidades dos campos de estágio e do corpo docente (Ata 63, segundo primeiro período).

Foi pedido pela presidente aos membros da escola auxiliar de enfermagem, que fosse dado esclarecimento de quais as medidas tomadas por esta escola no assunto da criação de uma faculdade de enfermagem, assunto este tão comentado no meio médico e quais as contribuições dadas, ou pelo menos, qual o conhecimento dos membros daABEn-PI (Ata 42, primeiro período).

Os posicionamentos dos membros da ABEn, sobre o ensino da profissão, também foram ressaltados no segundo período do estudo, ou seja, nos conteúdos das atas correspondentes a 1995 e 2005, estando estes sistematizados semanticamente em uma única subcategoria.

Estes conteúdos, embora relacionados ao ensino, evidenciam as preocupações e posicionamentos dos enfermeiros sobre os cursos de capacitação técnica para profissionais e não mais aos cursos de formação. Tais evidências fortalecem a afirmação de que as representações sociais dos membros daABEn-PI orientavam suas condutas para as responsabilidades de capacitação dos profissionais da área e de seus próprios membros. As unidades de contexto seguintes respaldam tais inferências:

A reunião na sede da $A B E n-P I$, em caráter extraordinário, com o fim especial de discutir e apreciar o Projeto de "Capacitação da Equipe de Enfermagem na Prevenção do HIV/AIDS", coordenado por enfermeira da Universidade Federal do Piauí, e membro efetivo desta associação. Explicado rapidamente aos demais membros o motivo especial da reunião se fez uma breve exposição sobre o que é o projeto e a participação da ABEn-PI, como a instituição mantenedora do projeto em questão, tendo em vista que uma das finalidades da associação é de promover eventos culturais, como congressos, seminários, oficinas, etc. Adiretoria entendeu que o mesmo é de relevante para a classe e decidiu concordar com a proposição outorgando à presidente plenos poderes para celebrar 0 Convênio. (Ata $n^{\circ} 24$, segundo período).

A atitude crítica dessas enfermeiras em relação ao ensino de enfermagem, quer seja relacionado à formação de nível médio, à graduação, bem como a educação continuada, ancora-se na função fiscalizadora do exercício profissional que era exercida pelas $A B E n(s)$, no momento de sua criação, na realidade brasileira

As idéias que conformavam o posicionamento dessas enfermeiras no
Piauí circulavam em todo Brasil via boletins informativos da $A B E n$, como as cartas e outras informações que chegavam para a associação local. Neste sentido, ressalta-se a importante função das representações sociais da categoria, orientando o comportamento de seus grupos com relação ao ensino.

\subsection{Sentimentos em relação ao ensino da profissão}

Os sentimentos que as sócias da ABEn-PI nutriam em relação ao ensino da profissão estão expressos nas unidades de contexto dessa categoria, as quais trazem evidências do conteúdo representacional referente apenas ao período de 1959 a 1970. Duas subcategorias foram sistematizadas: autonomia quanto processo de formação do ensino de enfermagem e insegurança quanto às condições estruturais de criação de escola superior de enfermagem.

As sócias da ABEn-PI, no desejo de mudar uma situação existente no ensino das escolas de enfermagem, em que os médicos eram os professores, nutriam esse sentimento de autonomia que está assentado na própria história da enfermagem desde os seus primórdios, pois várias escolas de enfermagem nasceram atreladas às escolas de medicina e a própria $A B E n$, desde a sua criação, nutriu esse desejo de que o ensino de enfermagem fosse de autonomia das enfermeiras. Na unidade de contexto citada a seguir, percebe-se esse sentimento:

Os associados, presentes na reunião, criticaram a autorização para funcionamento de uma escola de enfermagem, com um currículo arcaico baseado Lei Federal 775/49, e com um corpo docente formado por cinco médicos, os quais, absolutamente, não atendem às exigências legais para o exercício da docência, em escolas superiores enfermagem (Ata 42, primeiro período).

O relato presente nas atas faz crítica a uma escola de enfermagem noutro contexto e, sutilmente, revela que as representações sociais produzidas no grupo nutriam o sentimento de autonomia da profissão.

Este sentimento está ancorado no desejo do grupo de enfermeiras da ABEn-PI de conduzir os destinos do ensino de enfermagem, sendo desenvolvido desde a criação da Associação, a partir da Escola de Enfermagem Anna Nery, pois as escolas de enfermagem com suas prerrogativas de legitimar o saber, conferir capital cultural e desenvolver o sentimento de pertença a instituição e de criar zonas de influência, se constituíam como elementos catalisadores da vida associativa ${ }^{(8)}$.

As sócias da $A B E n$ expressam também um sentimento de insegurança em relação às condições estruturais locais para instalação de curso de enfermagem que podem ser identificados em descrições como:

Disse não ser contrária ao funcionamento de uma faculdade de enfermagem, mas em primeiro lugar, que se estude o meio e dê condições não improvisadas e sim definitivas ou que embora funcionando em condições precárias, não dê como resultado, profissionais de condições mediocres (Ata $n^{\circ} 42$, primeiro período).

Essa insegurança ancorava-se, principalmente, na preocupação da categoria dos médicos assumirem a formação das enfermeiras, o que significava perda de espaço no campo profissional. Tal fato tinha sentido, considerando-se que o quantitativo de enfermeiras, no mercado de trabalho local, naquele período, era reduzido. De acordo com o trecho abaixo era preciso prepara,r com urgência, as enfermeiras para o magistério superior:

Quanto à escola superior de enfermagem foi ventilada a necessidade de preparo urgente para o magistério superior, devido as atuais exigências da reforma universitária, com referência ao professor de nível superior (Ata $n^{\circ} .63$ primeiro período).

3.4 Posicionamentos Sobre as Lutas da corporação de enfermagem Esta categoria apresentou posicionamentos dos membros da ABEn-PI 
sobre as lutas da enfermagem brasileira. No período de 1959 a 1970 foram sistematizadas duas subcategorias: conhecimento das lutas daABEn, difusão da profissão na sociedade.

O conhecimento das lutas nacionais da ABEn fortalecia a associação piauiense como um grupo social organizado, que mesmo com um contingente pequeno de sócias, mantinha relações e articulações com a ABEn-Nacional.

O fato histórico da construção da sede geral da associação brasileira em Brasilia exemplifica esse movimento, que mobilizou aABEn-PI na busca de recursos para a viabilização dessa edificação, que até os dias atuais tem uma significativa expressão para a enfermagem brasileira.

Nesse sentido, as preocupações das enfermeiras que participavam da associação local retratam as representações sociais de sua pertença a esse grupo social, quando se engajam no projeto de caráter nacional por uma causa da profissão como apontam as unidades de registro:

foi solicitada a contribuição das sócias das varias sessões para a construção da sede própria em Brasília, sendo a cota do Piauí um total de um mil e quinhentos cruzeiros (Ata 57, primeiro período).

As sócias também apresentavam atitudes para difundir a profissão na sociedade como uma atividade importante para a profissão:

A senhora presidente, com a palavra, salientou um assunto importante sobre a difusão da enfermagem tendo sido ela mesma convidada para ministrar aulas em um clube com grande proveito e entusiasmo dos presente (Ata 26, primeiro período).

Com relação a esses posicionamentos, na realidade local existem registros de participação das enfermeiras em programas da Radio Difusora de Teresina e realizando palestras nas escolas. Esses aspectos das representações nos remetem às relações de pertença desse grupo, que buscava divulgar a profissão na sociedade.

No que diz respeito ao período de 1995 a 2005 foi sistematizada uma subcategoria: representatividade da enfermagem nos Conselhos de Saúde, como mostra as unidades de contexto:

A presidente comunicou o resultado do Plenário da Comissão Pró-SUS, ocorrida no Centro Formador de Recursos Humanos Carlyle Guerra de Macedo, ficando escolhida como representante titular da ABEn-Seção

Piauí, o representante suplente do COREN-PI (ata $2^{\mathrm{a}}$, segundo período).

Com esses posicionamentos, os membros da ABEn Sessão Piauí, demonstravam a preocupação da categoria de se fazer representar nas instâncias políticas, como a ABEN-Nacional sempre fez e continua fazendo em sua trajetória de luta pela enfermagem brasileira.

\subsection{Atitude de Culto a Religião e Homenagens}

Esta categoria reúne as unidades de contexto referentes às atitudes do grupo de enfermeiras da ABEn-PI relacionadas ao culto a religião católica, no período compreendido entre 1959 a 1970, agrupados, semanticamente, na subcategoria denominada proximidade entre a fé e a religião.

As unidades de contexto que se referem às atitudes religiosas enfocam a importância com que o assunto era considerado, revelando a influência exercida pelas irmãs de caridade de São Vicente de Paulo no comportamento dos membros da associação. Existe uma riqueza de relatos que descrevem as celebrações litúrgicas realizadas para comemorar a páscoa, o natal, dentre outras comemorações religiosas, como revelam as unidades de registro abaixo:

Foi colocada em discussão a proposta de realização da páscoa do pessoal de enfermagem. Será na capela do HGV, no dia vinte de maio, em conjunto com o pessoal auxiliar, sem distinção de classe. A proposta foi aceita pelos presentes (Ata 39, primeiro período).

Ainda constante na ordem do dia foi lançada uma proposta a mesa, pedindo que a associação comemorasse o natal. Foi aceita a proposta pela mesa ficando deliberada uma reunião de diretoria a fim de elaborar o programa e enviar o resultado as sócias por meio de carta circular (ata n. ${ }^{\circ} 27$, primeiro período)

Essas atitudes estão ancoradas nos princípios da religião católica característica do grupo representado pelas irmãs de caridade, que exerciam influência religiosa na Associação, tendo em vista que foi sobre a liderança da Irmã Abrahide Alvarenga que se criou a ABEN-PI. Portanto, nessa proximidade que as enfermeiras daABEn-PI tiveram com as irmãs, muitas vezes, misturavam-se assuntos profissionais com os assuntos religiosos até porque, algumas religiosas eram também enfermeiras. Essa proximidade com as irmãs perdurou até metade da década de oitenta quando as religiosas fecharam a Escola Auxiliar de Enfermagem e saíram do Estado.

No segundo período do agrupamento das atas foram sistematizados os posicionamentos das sócias da ABEn-PI no que se refere as homenagens prestadas as ex-presidentes da Associação e as enfermeiras aposentadas. Nesse sentido várias solenidades foram organizadas como inauguração do painel fotográfico das ex-presidentes, jantar comemorativo e missa em ação de graças como retratam as unidades de contexto

foi discutido acerca das atividades para a festa de encerramento da gestão (triênio 95/98) onde foram sugeridas homenagens às ex-presidentes com galeria de fotos e homenagem as aposentadas, com placa alusiva e solenidade de posse da nova diretoria (ata $n^{0} 16$, segundo período)

Foi importante perceber nessa categoria, ainda na década de noventa, traços religiosos nos ritos das homenagens as enfermeiras.

\section{CONSIDERAÇÕES FINAIS}

O conteúdo representacional apreendido na análise das atas evidenciou conhecimentos, posicionamentos e sentimentos das sócias da ABEn-PI, que nos permitiram compreender como o trabalho associativo foi desenvolvido pelas enfermeiras, naqueles períodos de tempo, e nos remeteram ao passado recente da profissão na realidade piauiense.

O estudo mostrou que as representações sociais sobre o ensino de enfermagem na realidade local foi a que teve maior expressão no conteúdo das atas do primeiro período, evidenciando como os membros da associação conheciam as estratégias de criação de escolas de enfermagem, tinham um posicionamento sobre as condições locais e capacitação de professores e nutriam um sentimento de autonomia em relação ao ensino. Com relação ao segundo período de tempo, as representações sociais sobre o ensino da profissão se distanciaram do ensino formal.

O culto a religião identificado no primeiro período, por influência das irmãs de caridade, foi uma das dimensões das representações sociais presentes na memória da $\mathrm{ABEn}-\mathrm{PI}$, que teve influencia direta dessa ordem religiosa, marcando o ideário da enfermagem no Piauí.

A circulação desses conhecimentos, posicionamentos e sentimentos entre a ABEn-PI e a ABEN Nacional reforçava o sentimento de pertença ao grupo profissional, mostrando a difusão das representações sociais dessa categoria e determinando as condutas dessas enfermeiras.

Ao concluir o estudo, pontuamos que a análise do conteúdo das atas da ABEn-Pi foi uma incursão num documento histórico que permanecia intocado, silenciado, e se mostrou da maior importância para a compreensão de aspectos da memória social da categoria das enfermeiras na realidade local. 


\section{REFERÊNCIAS}

1. Delgado, LAN. Memória, história e sujeito: substratos da identidade. Rev Assoc Bras História Oral 2000;3(3):109-15.

2. Sá CP. A estrutura das Representações Sociais e a Memória Coletiva. In: Coutinho MPL. Representações Sociais: Abordagem Interdisciplinar. João Pessoa (PB): Editora Universitária/UFPB; 2003.

3. Moscovici S. A representação social da psicanálise. Rio de Janeiro (RJ): Zahar; 1978

4. Minayo MCS. O Desafio do Conhecimento. São Paulo (SP): HUCITEC-ABRASCO; 1996.
5. Santos AMR, Nunes BMVT, Nogueira LT, Moura MEB, Vasconcelos, MRPV. Atuação da irmã de caridade Abrahide Alvarenga no Piauí: uma história a ser contada. Texto \& Contexto Enferm 2005;14(4):551-6.

6. Nunes BMVT Os primórdios do ensino de enfermagem no Piauí: lutas e conquistas na Universidade. Teresina (PI): EDUFPI; 2004

7. Santos SSC. Currículos de enfermagem no Brasil e as diretrizes - novas perspectivas. Rev Bras Enferm 2003;56(4):361-4.

8. Vale EG. ABEn: 75 Anos de democracia, ética e compromisso com a enfermagem Brasileira. Rev Bras Enferm 2001;53(4):153-4. 
